\title{
Unemployment Compensation Finance and Labor Market Rigidity*
}

\author{
Pierre Cahuc ${ }^{\dagger}$ and Franck Malherbet ${ }^{\frac{1}{5}}$ \\ This version: February 2001
}

\begin{abstract}
The systematic use of experience rating is an original feature of the U.S. unemployment benefit system. At first glance, it is likely that experience rating is not desirable in many European labor markets characterized by high firing costs. We provide a simple matching model of a rigid labor market including firing costs, temporary jobs and a minimum wage in order to analyze this issue. Our analysis leads us to argue that experience rating is likely to reduce unemployment and to improve the welfare of low skilled workers in France, and more generally for low skilled workers in a typical rigid Continental European labor market.
\end{abstract}

\section{Introduction}

The systematic use of experience rating is an original feature of the U.S. unemployment benefit system. In most states, unemployment benefits are financed by taxing firms in proportion to their separations. Experience rating is a way to require employers to contribute to the payment of unemployment benefits they create through their firing decisions. It is striking that experience rating is absent from the unemployment compensation systems of other OECD countries, where benefits are usually financed by taxes on payrolls, paid by employers or employees, and by government contributions (Holmlund, 1998). Is experience rating only adapted to the U.S. labor market? Would it be suitable in other countries? Indeed, the U.S. labor market is specific, to the extent that it is always considered as being dramatically flexible: There is no job protection (OECD, 1999) and the minimum wage is low with respect to many other OECD countries (OECD, 1998). Is experience rating suitable only on a very flexible labor market, and not desirable if the labor market faces strong job protection and high minimum wage?

Many contributions have been devoted to the consequence of experience rating on unemployment and welfare (see Holmlund, 1998, for a survey).

Feldstein (1976) has been among the first to offer a theoretical analysis of experience rating. Feldstein presents a model of temporary layoffs, which are frequent in the U.S. economy. He considers the behavior of a firm, with an exogenous number of employees, facing demand shocks. He argues that the unemployment insurance subsidy has a very large impact on the rate of

\footnotetext{
*We thank Paul Beaudry, Jean-Pascal Benassy, Etienne Lehmann, Olivier L'Haridon and André Zylberberg for their comments.

${ }^{\dagger}$ Université Paris 1, Eurequa, Crest, IZA, and Institut Universitaire de France, Email: cahuc@univ-paris1.fr. Address: 106-112 boulevard de l'hôpital, 75013, Paris, France.

${ }^{\ddagger}$ Université Paris 1-Eurequa and CREST-INSEE. Email: malherbe@ensae.fr
} 
unemployment, causing layoffs when they would not otherwise happen, and magnifying the size of the layoffs that do occur. Feldstein concludes his analysis by stressing that "if there were full experience rating in the unemployment insurance tax and if benefits were taxed like other income, the subsidy to temporary layoffs would be eliminated. Unemployment insurance could then continue to provide protection for those who are temporarily laid off without any distortion in their behavior" (Feldstein, 1976, p 956). However, Feldstein's conclusion has been challenged by Burdett and Wright (1989), who argue that experience rating increases unemployment under reasonable conditions if the number of employees is not an exogenous number, as Feldstein assumed, but is chosen optimally by the employer. Marceau (1993) reaches close conclusions in a framework in which there is Cournot competition on the market for the good produced by firms. Marceau shows that if there is free entry and exit, average industrial employment may be a decreasing function of the experience rating because the number of firms in the industry decreases with this parameter.

All these papers consider the consequence of experience rating on temporary layoffs. It is assumed that a pool of workers is attached to the firm, and do not find a job elsewhere when unemployed. As Feldstein (1976) stressed, this analysis is likely to be relevant in the manufacturing sector in the U.S., but temporary layoffs are scarce in most European labor markets. Accordingly, some contributions have looked at the consequence of experience rating in an equilibrium model of unemployment allowing for workers mobility accros firms. In this framework, experience rating has the same type of consequence as a combination of an increase in firing cost and a decrease in the payroll tax. As shown by Mortensen (1994), Millard and Mortensen (1997) and Mortensen and Pissarides (1999a,b), an increase in firing costs has an ambiguous impact on unemployment: It reduces both job creation and job destruction. The decrease in the payroll tax is usually beneficial to employment. Millard and Mortensen (1997) find that increasing experience rating decreases unemployment for reasonable parameters values in a search and matching model, with endogenous job destruction and wages bargained at the firm level. As Millard and Mortensen do not explicitly introduce a balanced budget for the unemployment benefit system, the increase in experience rating has exactly the same effect on unemployment as a rise in firing costs. Actually, it can be argued that introducing a balanced budget constraint would magnify the decrease in unemployment due to experience rating, since the payroll tax should be reduced by the increase in experience rating. From this point of view, Albrecht and Vroman (1999) contribution is of particular interest because they explicitly introduce a balanced budget constraint for the unemployment benefit system. They examine the consequence of experience rating in an efficiency wage model where workers heterogeneity gives rise to imperfect monitoring and endogenous layoffs. They compare two self-financing unemployment compensation systems: One in which benefits are financed by a proportional payroll tax and another in which firms are taxed in proportion to their separations. They find that experience rating is favorable to employment, wage and production for any level of unemployment benefit. The reason being that experience rating, which increases separation costs, induces firms to pay higher wages in order to avoid layoffs due to shirking. Thus, Albrecht and Vroman are able to show that one gets higher wages, lower unemployment and higher production with experience rating for relevant parameters values.

Generally, empirical analysis of experience rating yields support to Feldstein's analysis. Topel (1983) finds that unemployment insurance subsidy due to payroll taxes accounts for more than a quarter of layoffs in his data set. The series of papers of Anderson and Meyer (1993, 1994, 2000) sheds light on the effects of experience rating in a broad variety of cases in the United States. 
Anderson and Meyer (2000) is of particular interest since the authors provide a detailed analysis of the 1984 Washington state legislation switch from a payroll tax system to an experiencerated system. This natural experiment provides good evidence on the effects of experience rating compared to a payroll tax system and thus may underline some prominent features of a potential reform of the unemployment benefits scheme in Continental Europe.

Overall, the contributions which analyze the consequence of experience rating in equilibrium unemployment models conclude that it is a good system. Nevertheless, it should be noticed that these contributions do not analyze how experience rating interacts with other features of the labor market. The aim of our paper is to tackle this issue. In this perspective, we use a simple equilibrium search and matching model, based on Mortensen and Pissarides (1994, 1999a) framework, which takes into account important rigidities of European labor markets. More precisely, we take into account job protection by introducing both firing costs and temporary jobs, which play a very important role in European countries (see OECD, 1999). We also introduce a minimum wage. Section 2 presents the model that will allow us to mimic both flexible and rigid labor markets. Section 3 is devoted to the analysis of the consequence of experience rating in a flexible labor market that is used as a benchmark to understand the influences of labor market rigidities on the efficiency of experience rating. Section 4 sheds some light on the influence of labor market rigidities and tries to assess the desirability of experience rating on a particular labor market often considered as very rigid: The French labor market. Section 5 provides some concluding comments.

\section{The model}

We consider a stochastic continuous time search and matching model with endogenous job destruction close to the models developed by Mortensen and Pissarides (1994, 1999a) and Pissarides (2000). At first, we focus on the presentation of the labor market. Then, the unemployment benefits system is described. A detailed presentation of the model is provided in appendix.

\subsection{The labor market}

We consider an economy with two goods: Labor and a numeraire good produced thanks to labor. There is an endogenous measure of firms. Each firm has only one job, that can be either filled or vacant. The labor force is composed of a continuum of infinite lived individuals, which measure is normalized to unity. Each individual offers one unit of labor per unit of time. Individuals have identical preferences, represented by a concave utility function with standard properties, denoted by $U(R)$, where $R$ denotes the instantaneous income. It is also assumed that workers do not save and do not have access to financial markets.

Vacant jobs and unemployed workers are matched together in pairs through an imperfect matching process. The rate at which vacant jobs and workers meet is given by the function $M(v, u)$, where $v$ and $u$ represent the vacancy and unemployment rates respectively. The matching function satisfies the standard properties: It is increasing, continuously differentiable, homogenous of degree one and yields no hiring if the mass of unemployed or vacant jobs is nil.

The model is meant to mimic flexible as well as rigid labor markets. In this perspective, it is important to make a distinction between newly created jobs, and the old jobs, that are much more stable in many economies with firing costs. Actually, many new jobs can be destroyed at low cost in Europe, and it makes sense to refer to new jobs, with low firing costs, as unstable jobs 
and to old jobs, with high firing costs, as stable jobs (Goux and Maurin, 2000). Accordingly, it is assumed that each worker can be in one of the following states: Unemployed, employed on a new (unstable) job or employed on an old (stable) job.

Each job-worker match is endowed with an irreversible technology requiring one unit of labor to produce $x$ units of output. The productivity is a random variable drawn from a general distribution $F(x)$ with support in the range $\left.]-\infty, x_{u}\right]$. Following the stochastic job matching literature (Pissarides, 2000), it is assumed that both jobs and workers have many unobservable characteristics likely to influence the productivity of each job-worker match. At a glance two vacant jobs may look the same for a worker. Similarly, two workers may appear identical to a firm. Meanwhile, when jobs and workers are matched together, one pair may be more productive than the other and it can be worth firing some workers newly hired. Accordingly, it is assumed that as soon as a firm and a worker are brought together they sign up for a contract without knowing the value of $x$. Once a contract is signed, the destruction cost of any new job amounts to $f_{n}+\tau_{n}$, where $f_{n} \geq 0$ is a firing tax redistributed thanks to lump sum transfers to all the workers, and $\tau_{n} \geq 0$ is a tax used to finance unemployment benefits. Each new job starts with a trial period that allows the employer to check the productivity $\left.x \in]-\infty, x_{u}\right]$ of the match. Low realizations of the productivity are then rejected according to an endogenous threshold, denoted by $x_{n}$. For the sake of simplicity, it is assumed that the trial period is infinitely small. This implies, in particular, that the measure of workers who are in the trial period is equal to zero. It will appear below that this way to represent the trial period yields simple insights on the crucial role of the trial period in an experience-rated system without any loss of generality.

On every job, productivity changes according to a Poisson process with arrival rate $\lambda$. Every time a match is hit by a shock, a new value of $x$ - assumed to be verifiable after the trial period - is drawn from the distribution $F(x)$. Any new job which value of $x$ is below the endogenous threshold $x_{n}$ is destroyed. New jobs have an additional source of destruction, due to institutional constraints, which imply that the firing cost changes according to a Poisson process with arrival rate $\alpha$. When a change occurs, the employer can either destroy the job at cost $f_{n}+\tau_{n}$, or continues and faces new firing costs amounting to $f_{s}+\tau_{s} \geq f_{n}+\tau_{n}$, where $f_{s} \geq f_{n}$ is the firing tax redistributed through lump sum transfers to all the workers, and $\tau_{s} \geq \tau_{n}$ is a tax used to finance unemployment benefits. A new job is transformed into a stable job provided that the value of $x$ is above an endogenous reservation value, denoted by $x_{s}$. As the firing cost is larger for stable jobs than for new jobs, new jobs yield a higher surplus. Thus, the reservation productivity for new jobs, $x_{n}$, is smaller than $x_{s}$, the reservation productivity for the transformation of new jobs into stable jobs. The same reasoning implies that stable jobs are destroyed when they are hit by a bad productivity shock, which level is below an endogenous threshold value, denoted by $x_{d}<x_{n}$. The history of jobs is summarized on Figure 1 .

The labor market flows are represented on Figure 2. They play a key role in the determination of the unemployment rate, which depends on the rates of job destruction and job transformation as well as the mass of vacant jobs. Let us analyze how the equilibrium values of these variables are influenced by features of the labor market such as wage setting, job protection and the unemployment benefit system.

\subsection{Unemployment benefits and wage setting}

Unemployed workers get an instantaneous income made of three elements. First, an exogenous income, denoted by $z$, coming from their own activity (home production, leisure...). Second, 


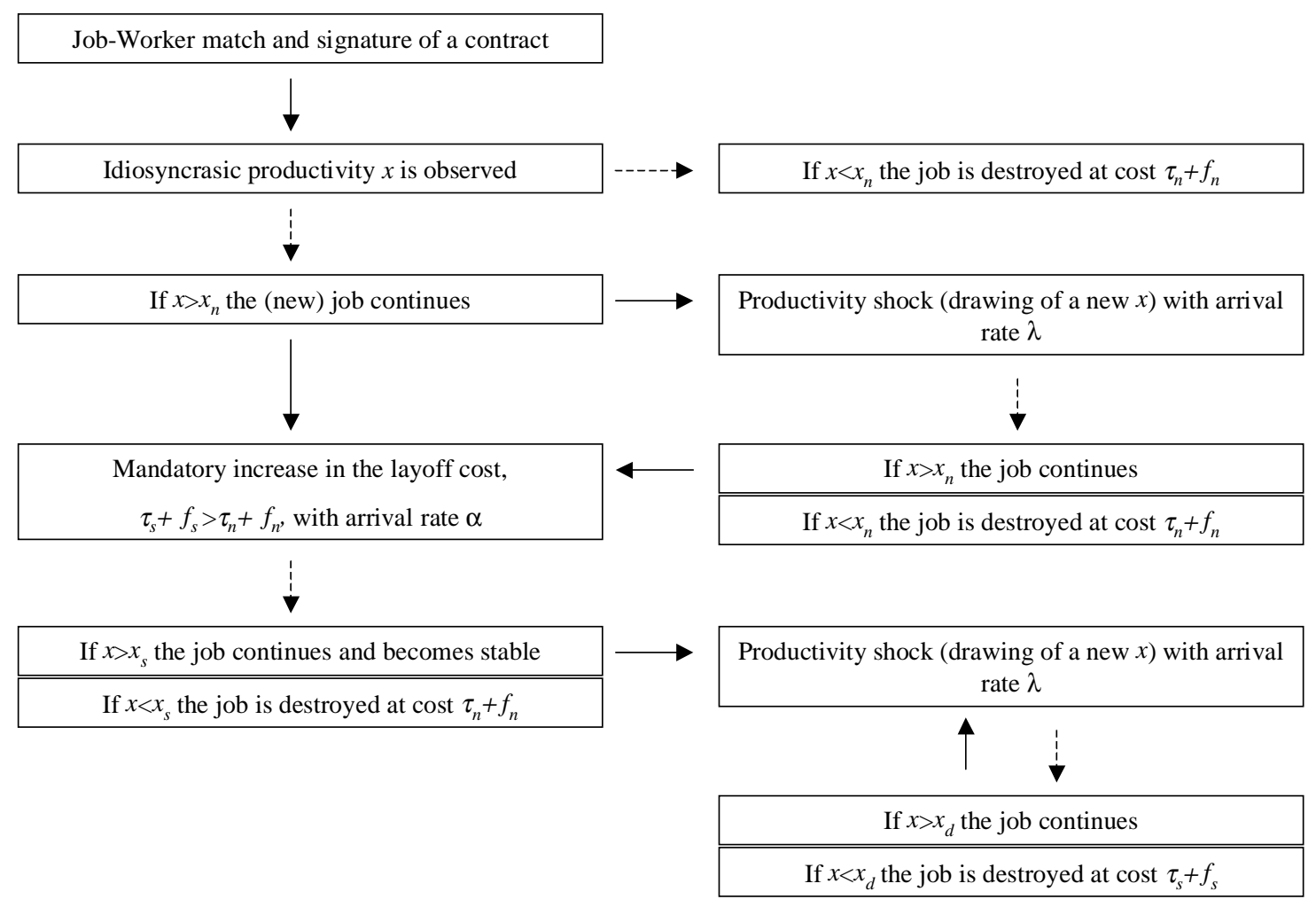

Figure 1: The history of a job-worker match. The arrows with a dotted line refer to endogenous decisions whereas the arrows with a continuous line refer to an exogenous event.

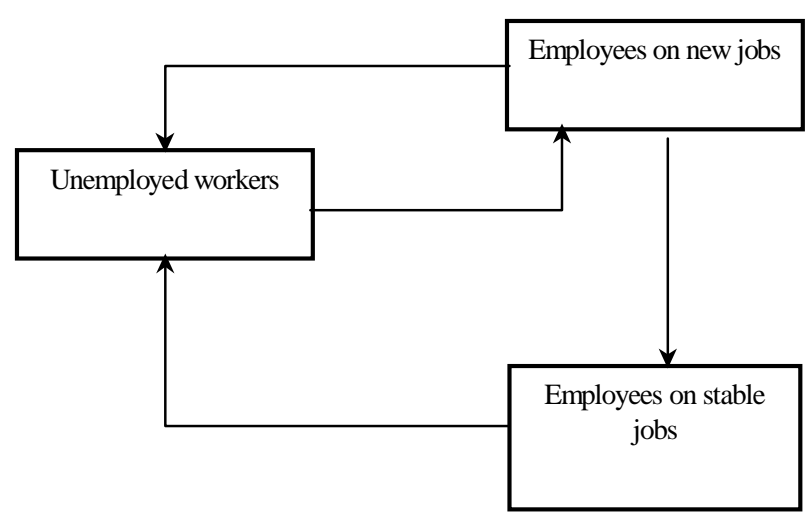

Figure 2: Labor market flows 
lump sum transfers resulting from firing $\operatorname{costs} f_{n}$ and $f_{s}$ which are not devoted to finance unemployment benefits. Third, unemployment benefits, denoted by $b$. Unemployment benefits are financed thanks to two instruments: A tax $\tau$ paid by each employer on each filled job, and a tax paid when a job is destroyed, denoted by $\tau_{n}$ and $\tau_{s}$ for a new job and a stable job respectively. This second type of tax is introduced in order to evaluate the consequence of experience rating. Accordingly, the expenditure of the unemployment benefit system is $u b$, whereas its resources per unit of time are:

$$
B=\tau \cdot(1-u)+\tau_{n} \cdot\left(\text { Mass of new jobs destruction) }+\tau_{s} \cdot(\text { Mass of stable jobs destruction) }\right.
$$

Matching models with a balanced budget constraint and a given replacement ratio exhibit multiple equilibria (Rocheteau, 1999). In order to avoid this problem, we shall henceforth look at the consequence of experience rating on unemployment and welfare for a given level of expenditure $B$, assuming a balanced budget. This allows us to look for the optimal degree of experience rating, for any level of expenditure, according to a well defined criterion, which can be either welfare or unemployment. It is worth noticing that assuming that the budget $B$ is given and balanced implies that unemployment benefit $b$ is endogenous: It is worth $B / u$. Moreover, if $\tau_{n}$ and $\tau_{s}$ are exogenous parameters, $\tau$ is necessarily an endogenous variable, which balances the required level of expenditure. If $\tau_{n}$ and $\tau_{s}$ are all equal to zero, there is no experience rating. If they are such that $\tau$ is worth zero, there is full experience rating.

Employed workers get a wage denoted by $w$. In our benchmark case, which represents a flexible labor market with neither firing cost nor minimum wage, it is assumed that the wage is set by employers. This simple assumption allows us to obtain a situation in which all workers receive the same wage, equal to $b+z$. It is worth noticing that this assumption has some important drawbacks at first glance. First, it is admittedly less general than assuming wage bargaining as it is done in most matching models of the labor market. However, it should be noticed that we want to look at the consequences of experience rating in the presence of a minimum wage. Introducing a minimum wage in a model with wage dispersion, as it is the case if wages are bargained over, gives rise to complexities (Cahuc and Zylberberg, 1999) that we want to avoid to be able to focus on comprehensible mechanisms. Second, assuming that workers do not get any share of the quasi-rent yielded by filled jobs gives rise to a very inefficient allocation, with too many jobs in equilibrium (see Hosios, 1990 and Pissarides, 2000). From this point of view, it would have been more relevant to assume that wages are determined through a wage posting process which yields an efficient outcome, that maximizes the expected utility of unemployed workers, as in Moene (1997), or Acemoglu and Shimer (1999). However, computing a wage posting equilibrium in a matching model with risk aversion and endogenous job destruction is a complex issue ${ }^{1}$ that is beyond the scope of this paper, devoted to the analysis of the consequences of labor market rigidities on the efficiency of different unemployment compensation finance schemes. Third, workers do not bear any risk in the flexible economy, since they are just paid their reservation wage whatever they do. Accordingly, one may wonder whether it is worth analyzing unemployment benefits in such a framework. On this particular issue, we argue that this not a problem as far as we are interested in the financing of the unemployment benefit

\footnotetext{
${ }^{1}$ In particular, employers cannot any more offer contracts with a constant wage only, because such contracts entail inefficient separations. Employers would have to post contracts that specify wages and severance payments.
} 
system and not in the design of the optimal benefits that workers should get. Moreover, we shall see that unemployment benefits can be welfare improving because they influence wages, and that our assumption allows us to illustrate in a simple way the response of wages to unemployment benefits.

Actually, our simple assumption turns out to be relevant for our purpose, which is merely to understand the impact of experience rating on flexible wages in order to see what changes are introduced by the minimum wage and firing costs.

\section{Experience rating on a flexible labor market}

Our benchmark case is a flexible labor market with a competitive wage and no job protection. Many contributions have shown that experience rating has a positive effect on employment and welfare in such a context. Our analysis can be split in two parts. First, we begin to study the theoretical properties of the model when an increase in the experience rating tax rate occurs. Second, we aim at fine tuning the theoretical analysis with some computational exercises.

\subsection{Theoretical analysis}

Let us begin to assume that there is no firing cost, $f_{n}=f_{s}=0$ and that experience rating applies on stable jobs only, $\tau_{n}=0, \tau_{s} \geq 0$. Moreover, the rate of transformation of new jobs into stable jobs is infinite $(\alpha \rightarrow \infty)$. This case represents a situation in which experience rating does not apply to the trial period: Only jobs that are destroyed after the trial period give rise to experience rating.

The equilibrium is represented on Figure 3 in the $\left(\theta, x_{d}\right)$ plane, where $\theta=v / u$ stands for the labor market tightness. The equilibrium values of the labor market tightness $\theta$ and the reservation productivity $x_{d}$ are determined by the intersept of a downwards sloping job creation curve and an upward sloping job destruction curve (see Appendix A, case 2). Intuitively, the job creation curve has a negative slope because a higher reservation productivity tends to increase the rate of job destruction. Accordingly, a higher reservation productivity for continuation of stable jobs entails a shorter expected duration of jobs. Thus, if the reservation productivity $x_{d}$ is increased, expected profits for new jobs are falling off, which induces entrepreneurs to create fewer jobs, that, in turn, leads to a decrease in the labor market tightness. The job destruction curve has a positive slope, because an increase in the labor market tightness tends to improve workers' outside opportunities, and, therefore, to raise the exit rate from unemployment, the expected utility of unemployed workers, and wages. Thus, if the labor market tightness is raised, the expected profits are falling off and the reservation productivity is increased, so that more jobs are terminated.

Now, let us look at the consequence of a rise in experience rating. These consequences are depicted on Figure 3- an analytical presentation is given in Appendix A, case 2. It induces a move from steady state equilibrium A to steady state equilibrium B. An increase in experience rating decreases destruction of stable jobs, which corresponds to an upward move of the job destruction curve. From this point of view, experience rating acts like a firing cost and tends to create a labor hoarding phenomenon. It can also be checked that experience rating decreases job creation by two channels. First, experience rating induces firms to create less vacant jobs. Accordingly, the job creation curve is shifting down, as shown by Figure 3. One must keep in mind that this mechanism takes account of the budget equilibrium of the unemployment 


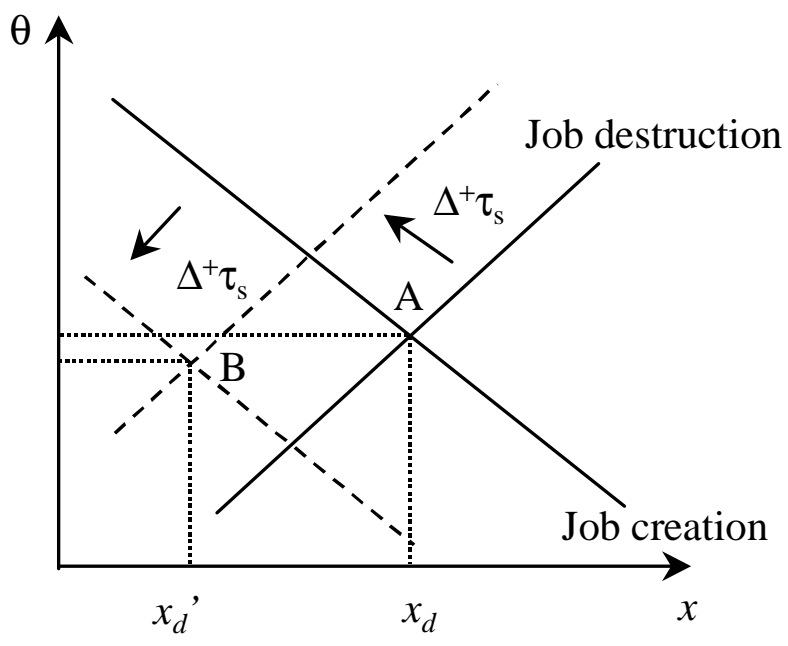

Figure 3: Effects of an increase in experience rating in the flexible labor market.

compensation system, which differs from the analysis provided by Millard and Mortensen (1997). Second, experience rating raises the reservation productivity at the end of the trial period.

Overall, experience rating diminishes both the job destruction of stable jobs and the labor market tightness - a formal proof is given in Appendix A, case 2. Therefore, its effect on unemployment is ambiguous and it is necessary to fine tune our results using computational exercises.

It is also worth giving some hints on the consequences of experience rating on welfare in the flexible economy. One can show - see appendix A, case 2 - that workers, who all get the same instantaneous utility $U(b+z)=U\left[\left(\frac{B}{u}\right)+z\right]$, benefit from positive unemployment benefits, because $\operatorname{Lim}_{B \rightarrow 0} d(B / u) / d B>0$. Accordingly, in our framework, it is worth introducing positive values of unemployment benefits. But, for positive values of unemployment benefits, the job destruction rate is too high, in the absence of experience rating because unemployment benefits induce a discrepancy between the social value of jobs surplus, which obtains by comparison of the productivity of the job, $x$, with the productivity outside the market, $z$, and the private value of jobs surplus, which is derived from the comparison of the job productivity free of taxes, $x-\tau$, with the workers reservation wage, $b+z$. In order to make this point clear, let us consider, for the sake of simplicity, a static environment. In that case, efficiency requires that all jobs with $x \geq z$ continue, but the private decisions of employers imply that they destroy jobs such that ${ }^{2}$ $x-\tau<z+b$. Accordingly, it appears that unemployment benefits induce a discrepancy between the private and the efficient job destruction decisions for two reasons. First, the fiscal externality stressed by Feldstein (1976) arises, since employers who fire workers do not take account of the increase in the tax induced by their action in the absence of experience rating. Accordingly, employers fire too many workers, which implies a too high value of the tax $\tau$, and too many job destructions. Second, the reservation wage, $w=b+z$, is increased by unemployment benefits. This also leads to too many job destructions ${ }^{3}$. For these two reasons, the job destruction rate

\footnotetext{
${ }^{2}$ Appendix A, case 1, precisely defines job destruction decisions in the dynamic matching model.

${ }^{3}$ Notice that this effect would also arise in a model with wage bargaining or with wage posting.
} 


\begin{tabular}{lllllll}
\hline \hline Parameters & $z$ & $\lambda$ & $h$ & $r$ & $f_{n}$ & $f_{s}$ \\
& .1 & .1 & .5 & .01 & 0 & 0 \\
\hline Endogenous variables & Job dest rate & Unemp. & spell & $u$ \\
& 0.059 per quarter & \multicolumn{1}{l}{1.58 quarter } & $8.5 \%$ \\
\hline
\end{tabular}

Table 1: Parameters value and features of the flexible labor market

is too high if there are positive unemployment benefits and no experience rating in the flexible economy. That is why it is worth using experience rating. In sum, in our benchmark economy, it appears that the welfare of workers can be maximized thanks to a combination of positive unemployment benefits and full experience rating.

\subsection{Computational exercises}

Our computational exercises illustrate the effects of experience rating in a more stringent manner. They suggest that some positive experience rating is favorable to both employment and welfare for a large range of plausible parameters values.

We follow Mortensen and Pissarides (1999a,b) in the calibration exercise. A matching function of the Cobb-Douglas form is assumed, such that $\ln [m(\theta)]=\frac{1}{2} \ln (\theta)$. The distribution of idiosyncratic shocks is assumed to be uniform on the support $[0,1]$. We assume a CRRA utility function: $U(R)=R^{1-\sigma} /(1-\sigma)$, with $\sigma=1.5$. The baseline parameters used in our computational exercise are reported in Table 1 . The time unit is the quarter and parameters $\lambda, z$, and $h$ are chosen so that the steady state implications of the model match reasonable values for the job destruction rate, the unemployment spell and the unemployment rate for the optimal replacement ratio, $b^{*}=0.84$, in the absence of experience rating, which is computed from Figure 4 , as explained below.

Henceforth the degree of experience rating, denoted by $\varepsilon$, is the proportion of the expected discounted cost of an unemployed worker. Namely, given that the exit rate from unemployment is $\theta m(\theta)\left[1-F\left(x_{n}\right)\right]$, the expected discounted cost of an unemployed worker is $b /\left[r+\theta m(\theta)\left[1-F\left(x_{n}\right)\right]\right]$, and $\varepsilon$ is the proportion of this cost paid by an employer when a worker is fired.

Figure 4 plots the welfare as a function of the budget $B$ for different degrees of experience rating, which applies after the trial period only. In the flexible labor market, welfare simply amounts to $U(b+z) / r$, since all workers get the same income. Figure 4 shows that welfare is maximized for a positive level of unemployment benefits and full experience rating $(\varepsilon=1)$. Namely, it appears that the efficient allocation is obtained for $B=0.055$ and $\varepsilon=1$ in the flexible economy. It is worth noticing that this result allows us to deduce that the unemployment rate reaches a minimum when there is full experience rating for a given level of expenditure $B=0.055$, because welfare merely amounts to $U\left[\left(\frac{B}{u}\right)+z\right] / r$.

It can be seen, on Figure 5, that experience rating induces a relatively small impact on the unemployment rate that decreases from $10.55 \%$, for $\varepsilon=0$, to $10.25 \%$, for $\varepsilon=1$.

Figure 6 shows the consequence of experience rating in the case in which it also applies to the trial period. In this situation, employers have to bear some firing costs, due to experience rating, when they fire workers during the trial period. Figure 6 plots the welfare as a function of $B$ for three levels of experience rating: $\varepsilon=0, \varepsilon=0.3, \varepsilon=0.6$, when experience rating applies to all jobs, including the trial period. It can be seen that the highest level of welfare 


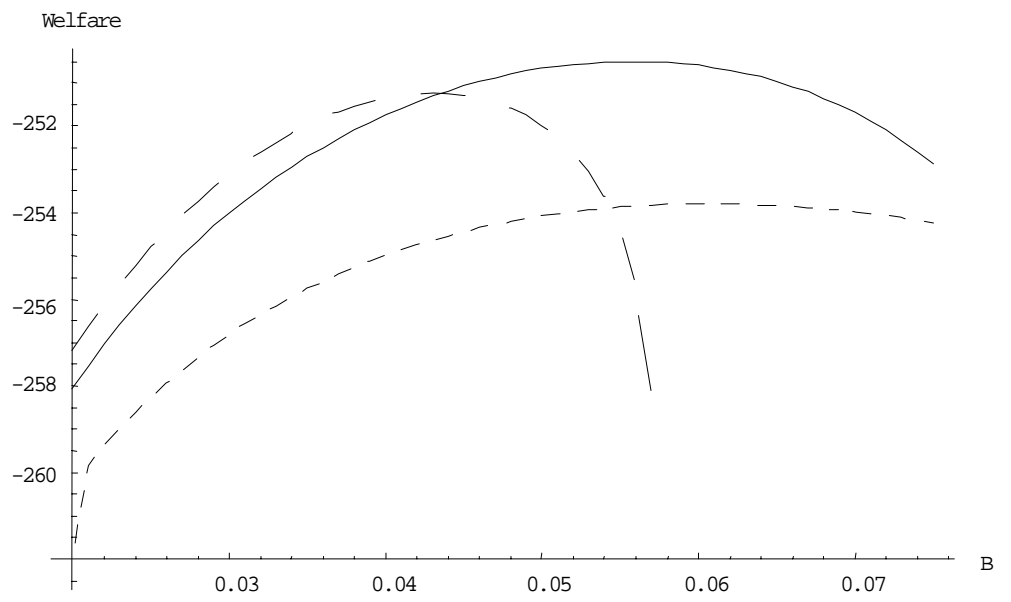

Figure 4: The consequence of changes in the budget $B$ on welfare, for $\varepsilon=0$ (short dashed line) $\varepsilon=1$ (continuous line), and $\varepsilon=1.5$ (long dashed line) when experience rating does not apply to the trial period.

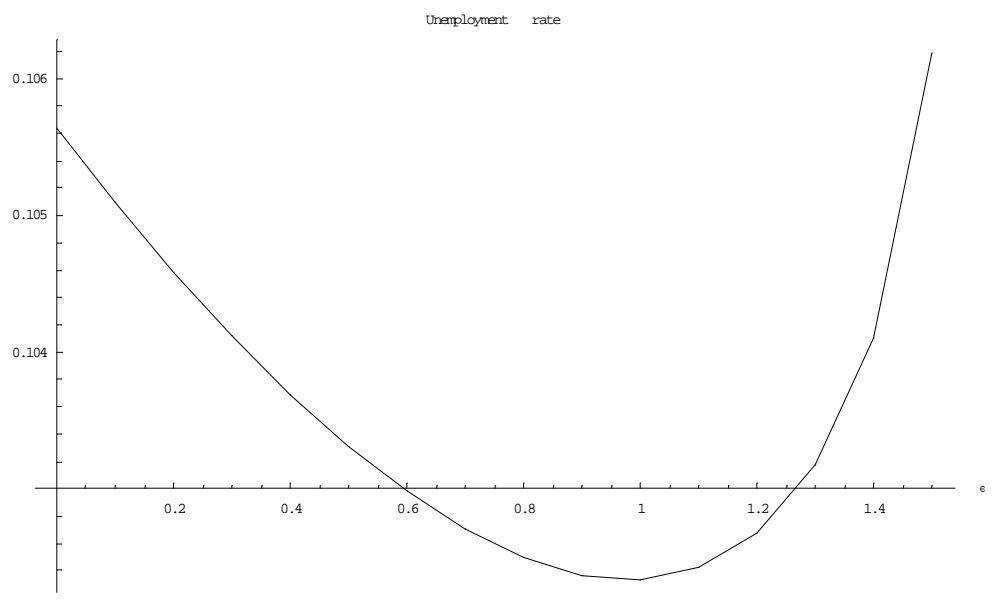

Figure 5: Experience rating and unemployment in the benchmark labor market with a trial period for $B=0.055$. 


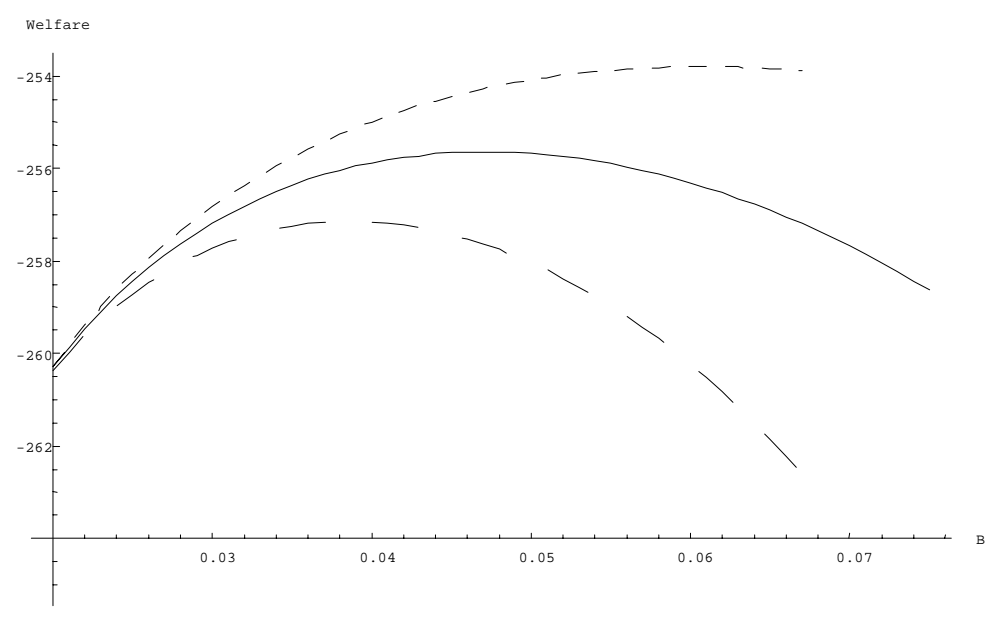

Figure 6: The consequence of changes in the budget $B$ on welfare, for $\varepsilon=0$ (short dashed line) $\varepsilon=0.3$ (continuous line), and $\varepsilon=0.6$ (long dashed line) when experience rating applies to the trial period.

obtains in the absence of experience rating. Other simulations, non reported here, indicate that welfare is maximized without experience rating, which means that it is not worth introducing experience rating if it applies to all jobs, including the trial period. It is important to notice that this result obtains because the proportion of layoffs at the end of the trial period is very high in our framework: It is worth $61 \%$ when $\varepsilon=0$. Accordingly, experience rating strongly discourages job creation if it applies to the trial period. Other parameters value, conducive to a lower proportion of layoffs at the end of the trial period, would imply that the optimal experience rating, applying to all jobs, would be positive, but lower than one. One can conclude that experience rating is worthwhile on a flexible labor market if it does not apply at the very beginning of the employment relationship when the uncertainty about matches quality is large. If the screening process of workers leads the employers to terminate many jobs, an efficient experience rating system has too apply after a well defined trial period.

It is often argued that experience rating is the same thing as firing costs. Our framework, allows us to show that this assertion is far from being completely right. Indeed, in our framework, experience rating has a different impact on unemployment than firing costs for a given level of expenditure $B$. Obviously, increasing firing costs - and thus the lump sum transfer gotten by each worker - and simultaneously decreasing the level of expenditure $B$ amounts to raise the degree of experience rating. However, in our framework, an increase in firing costs, for a given level of $B$, raises the unemployment rate, because the increase in the separation costs $f_{n}$ and $f_{s}$ is not compensated by a payroll tax decrease. The consequence of a firing tax hike for a given level of $B$ is illustrated by Figure 7 .

\section{Experience rating on a rigid labor market}

We are going to focus on two aspects of labor market rigidity: Job protection and the minimum wage, which play a very important role in Europe. We start our analysis by some computational exercises meant to underline the properties of our model when firing costs and/or a minimum 


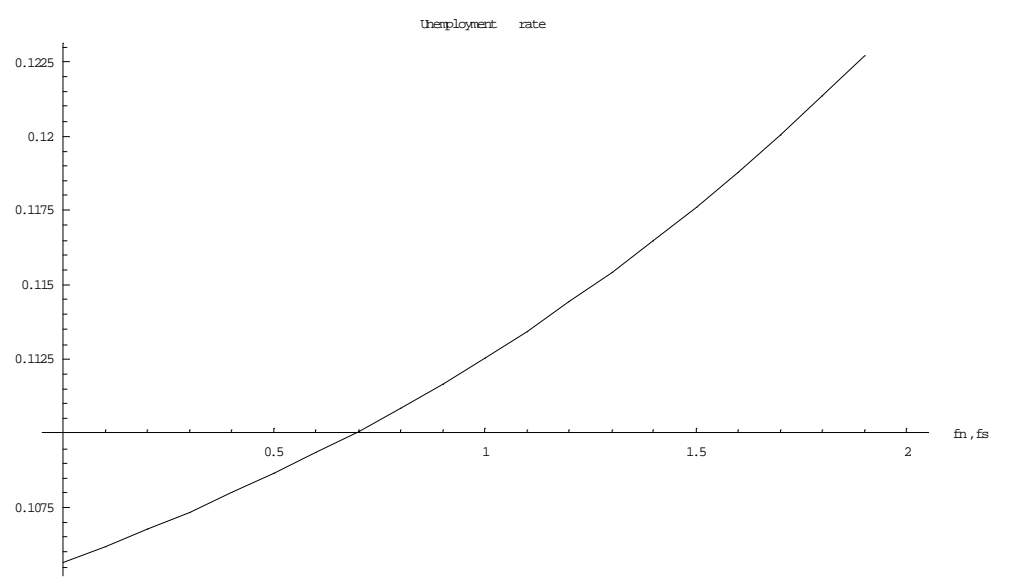

Figure 7: The consequence of firing costs $\left(f_{s}=f_{n}\right)$ on unemployment for a given budget $B=0.055$.

wage apply. Then, we evaluate the consequence of experience rating on a specific labor market, namely the French labor market, which has many features often met in continental European countries.

\subsection{Firing costs and minimum wage}

Job protection is likely to counteract the benefits of experience rating. The potential virtue of experience rating being to lower job destruction, it is doubtful whether it is worthwhile using experience rating when there are high firing costs. This point is illustrated by Figure 8, which represents the consequences of experience rating, applying only after the end of the trial period, when the firing costs on every job amount to 2 - the average production of a worker being about 0.8 per quarter in that case. One can see that experience rating is not any more useful to decrease unemployment when there is a strong job protection. Moreover, welfare also decreases with the degree of experience rating. More generally, it appears that the optimal degree of experience rating decreases with the level of job protection, and can even become negative, when job protection is very high.

The influence of the minimum wage on the efficiency of experience rating can easily be understood in our simple framework. Let us assume that a minimum wage is introduced in the flexible labor market, without any firing cost. It can be understood that experience rating can improve efficiency for two reasons. First, the minimum wage increases inefficient job destructions, with positive job surplus. Experience rating - applying after the end of the trial period - is a way to counteract this type of inefficiency, independently of the unemployment benefit financing problem, because, in the presence of a minimum wage, it is worth introducing firing costs that are redistributed to employers as a subsidy lowering labor cost. Second, the fiscal externality stressed by Feldstein (1976) still exists when there is a minimum wage, since the labor cost amounts to $w+\tau$ in the absence of experience rating, $\tau$ being taken as given by each employer.

As shown by Figure 9, assuming that the minimum wage entails an unemployment rate 

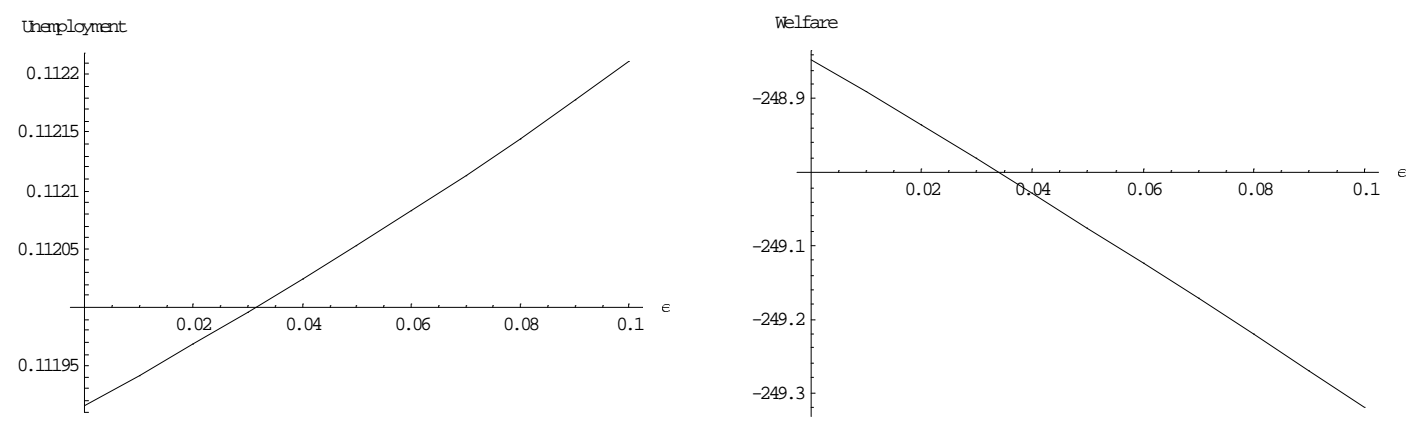

Figure 8: Experience rating with a flexible wage and high firing costs $\left(f_{s}=f_{n}=2\right)$.

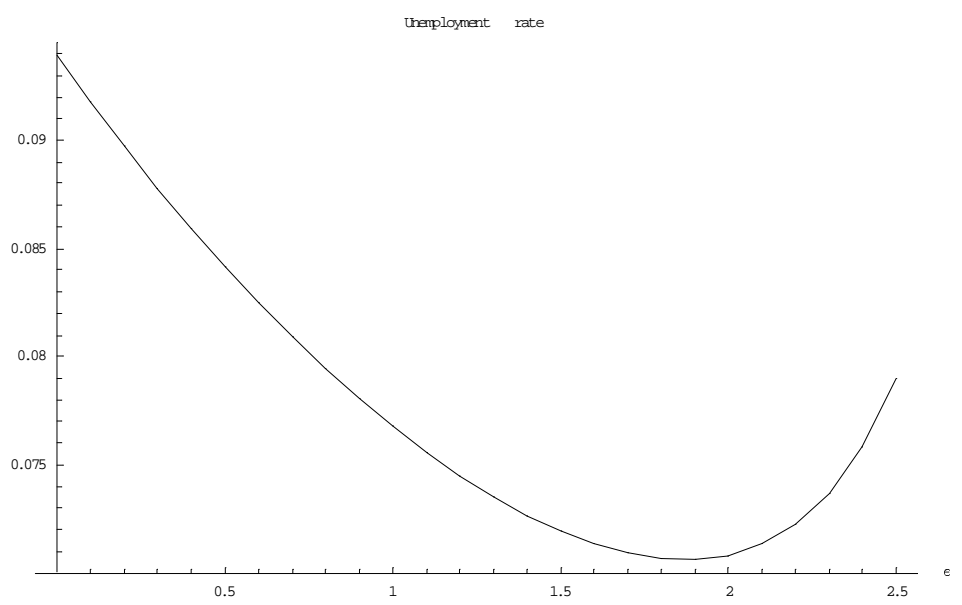

Figure 9: Experience rating in the labor market with a minimum wage and no firing cost. 


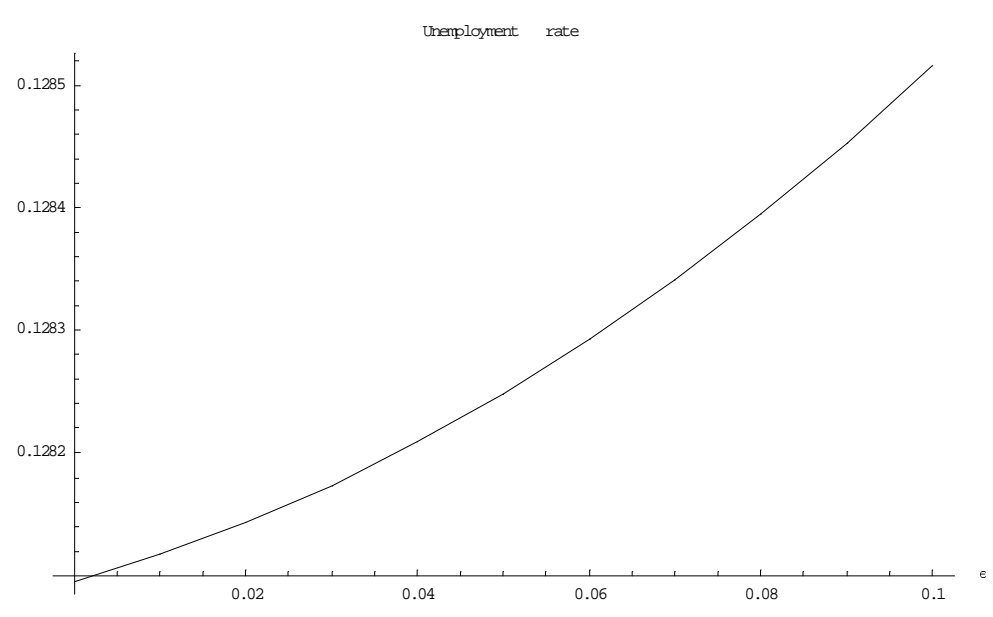

Figure 10: Experience rating in the labor market with a minimum wage and high firing costs $\left(f_{s}=f_{n}=2.5 \cdot w\right)$.

of about $9.5 \%$ in the absence of experience rating ${ }^{4}$, experience rating can give rise to a 2.5 percentage points decrease in the unemployment rate, whereas the decrease was very small in the absence of a minimum wage, as it is shown on Figure 5. Moreover, it appears that the degree of experience rating that minimizes the unemployment rate is larger than one. This is because experience rating counteracts the consequences of the fiscal externality and the minimum wage.

However, things turn out to be very different when there are high firing costs together with a minimum wage. In that case, one knows that firms do not necessarily destroy too many jobs, even if there is a minimum wage. It can even be the case that firing costs are so high that the job destruction rate is too low. This case is illustrated by Figure 10, which shows that it is not worthwhile introducing experience rating when there is a combination of a high minimum wage and high firing costs.

Overall, labor market rigidity has an ambiguous influence on the efficiency of experience rating. On one hand, job protection indubitably plays against experience rating. But on the other hand, a high minimum wage raises the efficiency of experience rating to fight against unemployment if job protection is low. Accordingly, one can conclude that the desirability of experience rating should be appreciated on every labor market, since it depends on institutional features that are specific to each country.

\subsection{A typical European labor market}

Now, let us turn to the issue of the efficiency of experience rating on a specific labor market. Namely, let us consider the French case, which is instructive insofar as many features of the French labor market are also present in European labor markets. Actually, job protection arises in a very specific form in such markets, because there are both stable jobs, that benefit from an important job protection, and unstable jobs, with a very short duration — see Goux and Maurin (2000), Cohen (1999). The spread of temporary jobs in Continental Europe, during

\footnotetext{
${ }^{4}$ This value of the unemployment rate corresponds to the value obtained for the parameters value chosen to mimic the French labor market (see Table 2), except for the firing costs which are set to zero here.
} 


\begin{tabular}{ll}
\hline \hline Unemployment rate & $16 \%$ \\
Exit rate from unemployment & $31 \%$ per quarter \\
Share of new jobs & $23 \%$ \\
Share of new matches transformed into stable jobs & $25 \%$ \\
Stable jobs destruction rate & $6 \%$ per quarter \\
Replacement ratio & $76 \%$ \\
\hline
\end{tabular}

Table 2: Features of the French labor market for unskilled workers.

the eighties and the beginning of the nineties (OECD, 1999), is a striking feature of European labor markets with high firing costs. In this context, some new questions arise: What is the real degree of job protection when temporary and permanent jobs coexist? Should both temporary and permanent jobs be concerned by experience rating?

Our model allows us to answer, to a certain extent, to these questions. In order to match the main features of the french labor market, according to the empirical contribution of Goux and Maurin (2000), it has been assumed that the typical length of a new non protected job is one year $(\alpha=0.25)$. A new job has a low firing cost, that amounts to $5 \%$ of the yearly wage. A stable job has a higher firing cost, that amounts to $50 \%$ of the yearly wage. We also have chosen to focus on the situation of the unskilled workers, who are paid a minimum wage. Accordingly, the minimum wage has been chosen to get an unemployment rate of $16 \%$ in the absence of experience rating. Table 2 presents ${ }^{5}$ the main features of the labor market that arise with the selected parameters value when there is no experience rating.

The effect of experience rating on unemployment and welfare is illustrated by Figure 11. We distinguish two cases: First, experience rating may apply to all jobs, including the trial period, second, to stable jobs only. Moreover, we look at the consequence of experience rating on unemployment, on the utilitarian criterion - which corresponds to the weighted sum of the workers' welfare - on the welfare of the unemployed workers and on the welfare of the employees on new jobs. Globally, Figure 11 shows that the unemployment rate reaches a minimum, and the different measures of welfare a maximum, for a positive value of experience rating in all cases. Thus, experience rating is worthwhile: It decreases unemployment and improves welfare even in the case where it also applies to the trial period. Even if firing cost are relatively high in France, the presence of temporary jobs and of a minimum wage make experience rating desirable for the low skilled workers. This result is very robust in our framework: It holds in a large range of plausible parameters values.

Our model also sheds light on the way experience rating should be applied on European labor markets. Given that only a low share of new matches are transformed into stable jobs (about 25\% as shown in Table 2), our model suggests that experience rating should not apply to new jobs - namely fixed-term jobs in France, where $80 \%$ of hirings are fixed-term jobs - which allow the employer to screen the employees. Obviously, introducing experience rating on stable jobs only induces an increase in the proportion of new jobs, since the new jobs destruction rate is raised and the stable jobs destruction rate is decreased by experience rating. A priori, this is detrimental to workers who are not employed on a stable job. However, it appears that this phenomenon is not really a problem here, since both unemployed workers and employees on new

\footnotetext{
${ }^{5}$ Parameters value are identical to those defined in Table 1 , except for $z=0.3, B=0.03$, and the wage, which is now exogenous: $w=0.64$.
} 

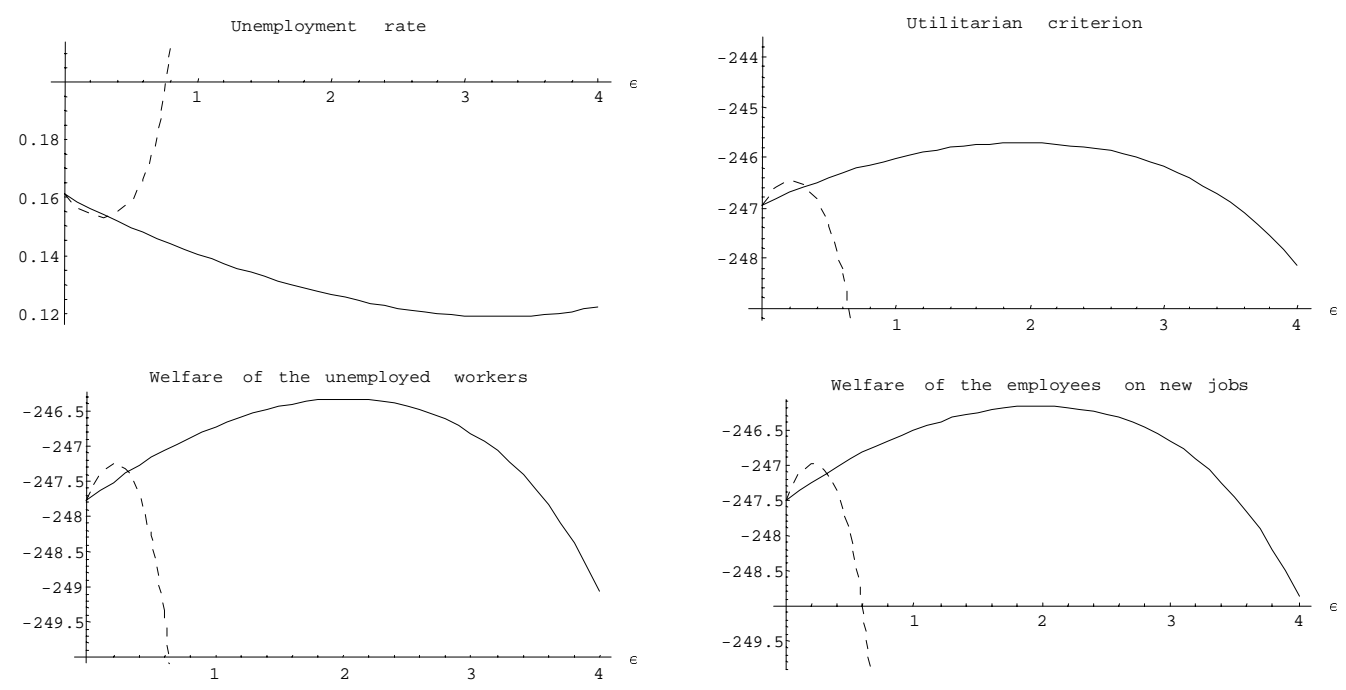

Figure 11: Experience rating, unemployment, and welfare, on the French labor market. Experience rating applies either to all jobs (dashed lines) or to stable jobs only (continuous lines).

jobs, who are those who suffer from the spread of job instability, benefit from experience rating introduced in such a way.

\section{Conclusion}

In this paper, we have provided a model of a rigid labor market including firing costs, temporary jobs and a minimum wage. This model leads us to argue that experience rating is likely to reduce unemployment and to improve labor market efficiency for low skilled workers in France, and more generally for low skilled workers in a typical rigid Continental European labor market. These results suggest that the combination of minimum wage, temporary jobs and firing cost met in Continental Europe gives rise to a form of labor market regulation where experience rating is worthwhile.

Obviously, our model has some limitations that future work should go beyond. First, workers heterogeneity is not taken into account. Actually, experience rating is likely to induce firms to substitute workers with short expected unemployment durations to workers with long expected unemployment duration, because the cost of the former is lower in case of separation. From this point of view, experience rating may be detrimental to very low skilled workers, whose unemployment spell is long. It is important to take this feature into account to evaluate the robustness of our results. Second, ex ante firms heterogeneity is not taken into account. The introduction of experience rating induces an increase in the tax burden in sectors with high labor turn-over and a decrease in the others. It is important to evaluate the consequences of such redistributive effects on the employment level of each sector to obtain a complete picture of the effect of experience rating (Deere, 1991). Third, we have limited the analysis to the segment of the labor market with a binding minimum wage when we focused on the European situation. It would be worth taking account of the interactions between this segment and the 
others in which wages are bargained by social partners. Fourth, our model does not account for the macroeconomic environment. Analyzing the incidence of experience rating on welfare and unemployment when the economy is subject to both idiosyncratic and macroeconomic shocks is on our research agenda. 


\section{References}

Acemoglu, D. and Shimer, R. (1999), "Efficient Unemployment Insurance", Journal of Political Economy, 107, pp. 893-928.

Albrecht J., and Vroman S., (1999), "Unemployment Finance and Efficiency Wages", Journal of Labor Economics, 17(1), pp. 141-167.

Anderson P., and Meyer B., (1993), "Unemployment Insurance in the United States: Layoff Incentives and Cross Subsidies", Journal of Labor Economics, 11(2), pp. 70-95.

Anderson P., and Meyer B., (1994), "The Effects of Unemployment Insurance Taxes and Benefits on Layoffs Using Firm and Individual Data”, NBER Working Paper N 4960.

Anderson P., and Meyer B., (2000), "The Effects of the Unemployment Insurance Payroll Tax on Wages, Employment, Claims and Denials", Journal of Public Economics, 78, pp. 81-106.

Burdett K., and Wright R., (1989), "Unemployment Insurance and Short Time Compensation: The Effects on Layoffs, Hours per Worker and Wages.", Journal of Political Economy, 97, pp. 1479-1496.

Cahuc P., and Zylberberg A., (1999), "Job Protection, Minimum Wage and Unemployment”, Cepremap Working Paper nº914.

Card. D., and Levine P., (1994), "Unemployment Insurance Taxes and the Cyclical and Seasonal Properties of Unemployment”, Journal of Public Economics, 53, pp. 1-29.

Cohen D., (1999), "Welfare Differentials Across French and US Labor Markets: a General Equilibrium Interpretation", Cepremap Working Paper n 9904.

Deere, R.D., (1991), "Unemployment Insurance and Employment", Journal of Labor Economics, $9(4), 307-24$.

Feldstein M., (1976), "Temporary Layoffs in the Theory of Unemployment", Journal of Political Economy, 84, pp. 937-957.

Goux D., and Maurin E., (2000), "Institutions et stabilité des emplois. Une analyse de la dynamique de la demande de travail selon l'ancienneté des salariés", Document de travail.

Holmlund B., (1998), "Unemployment Insurance in Theory and Practice", Scandinavian Journal of Economics, 100, pp. 113-141.

Hosios A., (1990), "On the Efficiency of Matching and Related Models of Search and Unemployment", Review of Economic Studies, 57, pp. 279-298.

Marceau N., (1993), "Unemployment Insurance and Market Structure", Journal of Public Economics, 52, pp. 237-249. 
Margolis D., and Fougère D., (2000), "Moduler les cotisations employeurs à l'assurance chômage: les expériences de bonus-malus aux Etats-Unis", forthcoming in Revue Française d'Economie.

Millard S., and Mortensen D., (1997), "The Unemployment and Welfare Effects of Labour Market Policy: A comparaison of the U.S. and U.K.", In Unemployment Policy: Government Options for the Labour Market, edited by Dennis J. Snower and Guillermo de la Dehesa. New York: Cambridge University Press.

Moene, E. (1997), "Competitive Search Equilibrium", Journal of Political Economy, 105, pp. $385-411$.

Mortensen D., and Pissarides C., (1994), "Job Creation and Job Destruction in the Theory of Unemployment”, Review of Economic Studies, 61, pp. 397-415.

Mortensen D., and Pissarides C., (1999a), "New Developments in Models of Search in the Labor Market", In Handbook of Labor Economics, 3 , Edited by O. Ashenfelter and D.Card. Elsevier Science.

Mortensen D., and Pissarides C., (1999b), "Job Reallocation, Employment Fluctuations and Unemployment", In Handbook of Macroeconomics, 1 , Edited by J. Taylor and M. Woodford. Elsevier Science.

OECD, (1998), Employment Outlook.

OECD, (1999), Employment Outlook.

Pissarides C., (2000), Equilibrium Unemployment Theory, 2nd edition, MIT Press.

Rocheteau, G., (1999), "Balanced-Budget Rules and Indeterminacy of the Equilibrium Unemployment Rate", Oxford Economic Papers, 51, pp. 399-409.

Topel, R., (1983), "On Layoffs and Unemployment Insurance", American Economic Review, 73, pp. 541-59. 


\section{Appendix A: The model}

\subsection{Value of jobs}

On every job, productivity changes according to a Poisson process with arrival rate $\lambda$. When a productivity shock occurs, a new value of productivity, $x$, is drawn from the distribution $F(x)$.

Denoting respectively by $f_{s}$ and $\tau_{s}$ the firing cost and the experience rating of a stable job, the asset value of a stable job with productivity $x$, denoted by $\Pi_{s}(x)$, satisfies the following equation:

$$
r \Pi_{s}(x)=x-w-\tau+\lambda\left\{\int_{-\infty}^{x_{u}} \operatorname{Max}\left[\Pi_{s}(\xi), \Pi_{v}-f_{s}-\tau_{s}\right] d F(\xi)-\Pi_{s}(x)\right\},
$$

where $\Pi_{v}$ stands for the value of a vacant job, $w$ for the wage and $\tau$ for the lump sum payroll tax paid for each filled job.

A new job faces two types of shocks. The first one is due to productivity shocks which occur at rate $\lambda$. The second one is due to a mandatory constraint which entails an increase in firing cost and experience rating. It is assumed that this constraint occurs according to a Poisson process with arrival rate $\alpha$. When such a shock happens, new jobs must either be destroyed or transformed into stable jobs. Accordingly, denoting respectively by $f_{n}$ and $\tau_{n}$ the firing cost and the experience rating of a new job, the asset value of a new job with productivity $x$, denoted by $\Pi_{n}(x)$, satisfies:

$$
\begin{aligned}
r \Pi_{n}(x) & =x-w-\tau+\lambda\left\{\int_{-\infty}^{x_{u}} \operatorname{Max}\left[\Pi_{n}(\xi), \Pi_{v}-f_{n}-\tau_{n}\right] d F(\xi)-\Pi_{n}(x)\right\} \\
& +\alpha\left\{\operatorname{Max}\left[\Pi_{s}(x), \Pi_{v}-f_{n}-\tau_{n}\right]-\Pi_{n}(x)\right\} .
\end{aligned}
$$

A vacant job costs $h$ per unit of time and is filled at rate $m(\theta)$. If the job gets filled, the productivity is not instantaneously observed. It is assumed that a contract is signed and that the newly created position starts by a trial period, which expected value is $\Pi_{t}$. This trial period is supposed to allow the employer to check the actual productivity of the match. Thus, the value of a vacancy, denoted by $\Pi_{v}$, satisfies:

$$
r \Pi_{v}=-h+m(\theta)\left(\Pi_{t}-\Pi_{v}\right) .
$$

Assuming that the destruction cost of a job at the end of the trial period is the same as the destruction cost of any new job, namely $f_{n}+\tau_{n}$, the expected value of a new match at the beginning of the trial period is given by:

$$
\Pi_{t}=\frac{1}{1+r \Delta}\left\{\Delta\left[\int_{-\infty}^{x_{u}} \xi d F(\xi)-w-\tau\right]+\int_{-\infty}^{x_{u}} \operatorname{Max}\left[\Pi_{n}(\xi), \Pi_{v}-f_{n}-\tau_{n}\right] d F(\xi)\right\}
$$

For the sake of simplicity, the trial period is infinitesimal, so that $\Delta$ goes to zero. Thus, we can rewrite $\Pi_{t}$ as:

$$
\Pi_{t}=\int_{-\infty}^{x_{u}} \operatorname{Max}\left[\Pi_{n}(\xi), \Pi_{v}-f_{n}-\tau_{n}\right] d F(\xi)
$$


Replacing (5) in (3) we obtain the expected value of a vacant job:

$$
r \Pi_{v}=-h+m(\theta)\left[\int_{-\infty}^{x_{u}} \operatorname{Max}\left[\Pi_{n}(\xi), \Pi_{v}-f_{n}-\tau_{n}\right] d F(\xi)-\Pi_{v}\right]
$$

\subsection{Job creation and job destruction equations}

Job creation is determined by a free-entry condition which reads as

$$
\Pi_{v}=0 .
$$

Jobs are destroyed when their expected value is lower than the destruction cost. It can easily be checked that the asset value of each type of job increases with its current productivity. Therefore, there exists a threshold value of productivity, denoted by $x_{n}$, below which new jobs are destroyed; $x_{n}$ being defined by:

$$
\Pi_{n}\left(x_{n}\right)=-f_{n}-\tau_{n}
$$

Similarly the reservation productivity $x_{s}$ beyond which a stable job is created satisfies:

$$
\Pi_{s}\left(x_{s}\right)=-f_{n}-\tau_{n},
$$

and the threshold value $x_{d}$ below which stable jobs are destroyed, satisfies:

$$
\Pi_{s}\left(x_{d}\right)=-f_{s}-\tau_{s} .
$$

\subsection{Labor market flows}

For any value of the productivity $x$ below $x_{n}$ a new match is not productive enough and thus is rejected. The matching process is such that are $M(v, u)$ matches per unit of time, where $u$ and $v$ respectively stand for the unemployment rate and the vacancy rate - the size of the labor force is normalized to one. The linear homogeneity of the matching function allows us to write the transition rate for vacancies into new jobs as $\left[1-F\left(x_{n}\right)\right] M(v, u) / v \equiv\left[1-F\left(x_{n}\right)\right] m(\theta)$ where $\theta=v / u$ refers to the labor market tightness. Similarly, the job finding rate is given by $\left[1-F\left(x_{n}\right)\right] M(v, u) / u \equiv\left[1-F\left(x_{n}\right)\right] \theta m(\theta)$. The properties of the matching function imply that $m(\theta)$ and $\theta m(\theta)$ are decreasing and increasing functions of the labor market tightness respectively. Due to the exogenous arrival rate $\alpha$, a new job must either end at cost $f_{n}+\tau_{n}$ or be transformed into a stable job, which destruction cost is $f_{s}+\tau_{s} \geq f_{n}+\tau_{n}$. When such an event occurs, jobs with productivity $x<x_{s}$ are destroyed. Taking into account both sources of job destruction, a worker employed on a new job becomes unemployed at rate $\lambda F\left(x_{n}\right)+\alpha \frac{\left[F\left(x_{s}\right)-F\left(x_{n}\right)\right]}{\left[1-F\left(x_{n}\right)\right]}$. As stable jobs face the same productivity shocks as the new job, the job destruction rate for stable jobs is given by a Poisson process with parameter $\lambda F\left(x_{d}\right)$.

The laws of motion of unemployment, of newly created positions and of old positions are given respectively by equations (11), (12) and (13) where $n$ and $s$ represent new and stable jobs respectively.

$$
\dot{u}=\lambda F\left(x_{d}\right) s+\lambda F\left(x_{n}\right) n+\alpha \frac{\left[F\left(x_{s}\right)-F\left(x_{n}\right)\right]}{\left[1-F\left(x_{n}\right)\right]} n-\theta m(\theta)\left[1-F\left(x_{n}\right)\right] u
$$




$$
\begin{gathered}
\dot{n}=\theta m(\theta)\left[1-F\left(x_{n}\right)\right] u-\lambda F\left(x_{n}\right) n-\alpha \frac{\left[1-F\left(x_{s}\right)\right]}{\left[1-F\left(x_{n}\right)\right]} n-\alpha \frac{\left[F\left(x_{s}\right)-F\left(x_{n}\right)\right]}{\left[1-F\left(x_{n}\right)\right]} n \\
\dot{s}=\alpha \frac{\left[1-F\left(x_{s}\right)\right]}{\left[1-F\left(x_{n}\right)\right]} n-\lambda F\left(x_{d}\right) s
\end{gathered}
$$

In a steady state, where $u, n$ and $s$ are constant, one gets a Beveridge curve which equation is given by:

$$
u=\frac{\lambda F\left(x_{d}\right)\left[\lambda F\left(x_{n}\right)+\alpha\right]}{\theta m(\theta)\left\{\lambda F\left(x_{d}\right)\left[1-F\left(x_{n}\right)\right]+\alpha\left[1-F\left(x_{s}\right)\right]\right\}+\lambda F\left(x_{d}\right)\left[\lambda F\left(x_{n}\right)+\alpha\right]}
$$

The Beveridge curve equation (14) shows that the unemployment rate depends on the rates of job destruction and job transformation as well as the labor market tightness.

\subsection{Budget equilibrium}

The expenditure of the unemployment benefit system is $u b$. The resources of the unemployment benefit system, denoted by $B$, depend on the mass of every type of job and on their destruction rate. They correspond to the sum of the payroll taxes $\tau(1-u)$, and the revenue of experience rating on new jobs and stable jobs:

$$
B=\tau(1-u)+\tau_{n}\left\{u \theta m(\theta) F\left(x_{n}\right)+n\left[\lambda F\left(x_{n}\right)+\alpha \frac{\left[F\left(x_{s}\right)-F\left(x_{n}\right)\right]}{\left[1-F\left(x_{n}\right)\right]}\right]\right\}+\tau_{s} s \lambda F\left(x_{d}\right)
$$

\subsection{The equilibrium}

One can now solve the model for all the unknowns in the steady state. There are ten unknown variables - the destruction thresholds $x_{n}$ and $x_{d}$, the transformation threshold $x_{s}$, the labor market tightness $\theta$, the wage $w$, the lump sum payroll tax $\tau$, the unemployment rate $u$, the mass of new jobs $n$, the mass of stable jobs $s$, and the unemployment benefits $b$. Henceforth, we will define a set of four equations that determines the equilibrium values of $\theta, x_{s}, x_{d}$ and $x_{n}$. The other endogenous variables being easily deduced from those values. Indeed, let us remark that (11), (12), (13) implicitly define the steady state value of the unemployment rate $u$, the mass of new jobs $n$ and of stable jobs $s$, as functions of $\left(\theta, x_{d}, x_{n}, x_{s}\right)$, and let us respectively denote these functions by $u\left(\theta, x_{d}, x_{n}, x_{s}\right), n\left(\theta, x_{d}, x_{n}, x_{s}\right)$ and $s\left(\theta, x_{d}, x_{n}, x_{s}\right)$. Similarly, (15) allows us to write the payroll tax rate as $\tau\left(\theta, x_{d}, x_{n}, x_{s}\right)$. The definition of the unemployment benefits yields $b\left(\theta, x_{d}, x_{n}, x_{s}\right)=B / u\left(\theta, x_{d}, x_{n}, x_{s}\right)$ whereas the wage, when it is endogenous, can be written as $w\left(\theta, x_{d}, x_{n}, x_{s}\right)=b\left(\theta, x_{d}, x_{n}, x_{s}\right)+z$.

We distinguish three cases. First, we present the generic model with an endogenous wage set by employers. Second, we study a limit case of this generic model without any firing cost, that corresponds to our flexible benchmark. Finally, we consider the case in which there are firing costs and a binding minimum wage. 


\subsubsection{Case 1: The generic model with endogenous wage}

In order to determine the equilibrium values $\left(\theta, x_{d}, x_{n}, x_{s}\right)$, we start by defining the endogenous destruction threshold for stable jobs. Combining equations (10) and (1) at $x=x_{d}$, the threshold value $x_{d}$ satisfies

$$
\begin{aligned}
x_{d} & =w\left(\theta, x_{d}, x_{n}, x_{s}\right)+\tau\left(\theta, x_{d}, x_{n}, x_{s}\right)-(r+\lambda)\left(f_{s}+\tau_{s}\right) \\
& -\lambda\left[\int_{x_{d}}^{x_{u}} \Pi_{s}(\xi) d F(\xi)-F\left(x_{d}\right)\left(f_{s}+\tau_{s}\right)\right],
\end{aligned}
$$

then computing $\Pi_{s}(x)-\Pi_{s}\left(x_{d}\right)$ thanks to (1) and using the definition (10) of $x_{d}$, the expected value of a stable job can be expressed as

$$
\Pi_{s}(x)=\frac{x-x_{d}}{r+\lambda}-f_{s}-\tau_{s} .
$$

Finally, substituting this expression for $\Pi_{s}(x)$ into (16), one gets the Job Destruction equation for Stable jobs (JDS):

$$
x_{d}=w\left(\theta, x_{d}, x_{n}, x_{s}\right)+\tau\left(\theta, x_{d}, x_{n}, x_{s}\right)-r\left(f_{s}+\tau_{s}\right)-\frac{\lambda}{\lambda+r} \int_{x_{d}}^{x_{u}}\left(\xi-x_{d}\right) d F(\xi) .
$$

The determination of the reservation productivity for new jobs, $x_{n}$, can be obtained in the same way. Combining equation (2) at $x=x_{n},(7)$ and equation (8), one gets:

$$
x_{n}=w\left(\theta, x_{d}, x_{n}, x_{s}\right)+\tau\left(\theta, x_{d}, x_{n}, x_{s}\right)-(r+\lambda)\left(f_{n}+\tau_{n}\right)-\lambda \int_{x_{n}}^{x_{u}} \Pi_{n}(\xi) d F(\xi),
$$

then computing $\Pi_{n}(x)-\Pi_{n}\left(x_{n}\right)$ for $x \leq x_{s}$ thanks to (2) and using the definition (8) of $x_{n}$, the expected value of a new job satisfies:

$$
\Pi_{n}(x)=\frac{x-x_{n}}{r+\alpha+\lambda}-f_{n}-\tau_{n} \text { for } x \leq x_{s} .
$$

Analogously, computing equation $\Pi_{n}(x)-\Pi_{n}\left(x_{u}\right)$ for $x \geq x_{s}$ thanks to (2), one gets:

$$
\Pi_{n}(x)=\frac{x-x_{u}}{r+\lambda}+\Pi_{h}\left(x_{u}\right) \text { for } x \geq x_{s} .
$$

Combining equations (19) and (20) together with (18), the Job Destruction equation for New jobs (JDN), writes as follows:

$$
\begin{aligned}
x_{n} & =w\left(\theta, x_{d}, x_{n}, x_{s}\right)+\tau\left(\theta, x_{d}, x_{n}, x_{s}\right)-\left\{r+\lambda\left[1-F\left(x_{s}\right)\right]\right\}\left(f_{n}+\tau_{n}\right) \\
& -\frac{\lambda}{r+\alpha+\lambda} \int_{x_{n}}^{x_{s}}\left(\xi-x_{n}\right) d F(\xi)-\frac{\lambda}{r+\lambda} \int_{x_{s}}^{x_{u}}\left(\xi-x_{u}\right) d F(\xi)-\lambda\left[1-F\left(x_{s}\right)\right] \Pi_{n}\left(x_{u}\right),
\end{aligned}
$$


where it remains to give the expression for $\prod_{n}\left(x_{u}\right)$. Using equation (2) for $x=x_{u}$, together with (17), (19) and (20) one gets:

$$
\begin{gathered}
{\left[r+\lambda F\left(x_{s}\right)+\alpha\right] \Pi_{n}\left(x_{u}\right)=x_{u}-w\left(\theta, x_{d}, x_{n}, x_{s}\right)-\tau\left(\theta, x_{d}, x_{n}, x_{s}\right)} \\
+\frac{\lambda}{r+\lambda+\alpha} \int_{x_{n}}^{x_{s}}\left(\xi-x_{n}\right) d F(\xi)+\frac{\lambda}{r+\lambda} \int_{x_{s}}^{x_{u}}\left(\xi-x_{u}\right) d F(\xi)-\lambda F\left(x_{s}\right)\left(f_{n}+\tau_{n}\right)+\frac{\alpha}{r+\lambda}\left(x_{u}-x_{d}\right)-\alpha\left(f_{s}+\tau_{s}\right) .
\end{gathered}
$$

One can now define the Job Creation equation (JC). The free-entry condition $\Pi_{v}=0$ together with equations (6), (19) and (20) allows us to write the JCF equation as:

$$
\begin{aligned}
\frac{h}{m(\theta)} & =\frac{1}{r+\lambda+\alpha} \int_{x_{n}}^{x_{s}}\left(\xi-x_{n}\right) d F(\xi)+\frac{1}{r+\lambda} \int_{x_{s}}^{x_{u}}\left(\xi-x_{u}\right) d F(\xi) \\
& -F\left(x_{s}\right)\left[f_{n}+\tau_{n}\right]+\left[1-F\left(x_{s}\right)\right] \Pi_{n}\left(x_{u}\right) .
\end{aligned}
$$

Finally, computing $\Pi_{s}\left(x_{s}\right)-\Pi_{s}\left(x_{d}\right)$ from (1), the Job Transformation equation (JT) reads as:

$$
x_{s}=x_{d}+(r+\lambda)\left(\tau_{s}+f_{s}-\tau_{n}-f_{n}\right) .
$$

Equations (JT), (JDN), (JDS) and (JC) (together with (21)) are the key equations allowing us to solve the model for $x_{d}, x_{n}, x_{s}$ and $\theta$.

\subsubsection{Case 2: The flexible labor market}

Let us assume that ther are no firing cost except for the experience rating. More precisely, let us assume that $\alpha \rightarrow+\infty$ and,$f_{s}=f_{n}=\tau_{n}=0$ whereas $\tau_{s} \geq 0$. In that case, experience rating does not apply to jobs destroyed at the end of the trial period. The case in which experience rating also applies to jobs destroyed at the end of the trial period corresponds to the assumption $\tau_{s}=\tau_{n} \geq 0$.

The basic equations of the model can be rewritten in this very simple setting. The flows equation (14) reads as:

$$
\lambda F\left(x_{d}\right)(1-u)=\theta m(\theta)\left[1-F\left(x_{s}\right)\right] u \Leftrightarrow u=u\left(\theta, x_{d}, x_{s}\right) .
$$

The budget equation (15) yields:

$$
B=\left[1-u\left(\theta, x_{d}, x_{s}\right)\right]\left[\tau+\tau_{s} \lambda F\left(x_{d}\right)\right],
$$

which implies, together with equations (22):

$$
\tau\left(\theta, x_{d}, x_{s}\right) \equiv \tau=\frac{B}{\left[1-u\left(\theta, x_{d}, x_{s}\right)\right]}-\tau_{s} \lambda F\left(x_{d}\right)=B\left[1+\frac{\lambda F\left(x_{d}\right)}{\theta m(\theta)\left[1-F\left(x_{s}\right)\right]}\right]-\tau_{s} \lambda F\left(x_{d}\right)
$$

By definition the wage is equal to $(B / u)+z$. Using equation (22), one gets: 


$$
w\left(\theta, x_{d}, x_{s}\right) \equiv w=\frac{B}{u\left(\theta, x_{d}, x_{s}\right)}+z=B \frac{\theta m(\theta)\left[1-F\left(x_{s}\right)\right]+\lambda F\left(x_{d}\right)}{\lambda F\left(x_{d}\right)}+z .
$$

Eventually, (JDS) and (JT) read as:

$$
\begin{aligned}
& x_{d}=w\left(\theta, x_{d}, x_{s}\right)+\tau\left(\theta, x_{d}, x_{s}\right)-r \tau_{s}-\frac{\lambda}{r+\lambda} \int_{x_{d}}^{x_{u}}\left(\xi-x_{d}\right) d F(\xi), \\
& x_{s}=x_{d}+\tau_{s}(r+\lambda)
\end{aligned}
$$

where (JDF) and (JTF) respectively refer to the Job Destruction equation and the Job Transformation equation in the Flexible economy. Now, it remains to define the job creation equation. Using the free entry condition $\Pi_{v}=0$ and equation (17) together with (6) and (JTF), one gets:

$$
\frac{h}{m(\theta)}=\int_{x_{d}+\tau_{s}(r+\lambda)}^{x_{u}}\left(\frac{x-x_{d}}{r+\lambda}-\tau_{s}\right) d F(x),
$$

where (JCF) refers to the Job Creation equation in the Flexible economy. Equations (JDF) and (JCF) (together with (25) and (24)) are the two fundamental equations allowing us to solve the model for $\theta x_{s}$ and $x_{d}$.

It can be easily checked that (JCF) has a negative slope in the $\left(\theta, x_{d}\right)$ plane. Differentiating (JDF) yields:

$$
\begin{aligned}
\left.\frac{\partial x_{d}}{\partial \theta}\right|_{J D F} & =\frac{(r+\lambda) \frac{\partial g\left(\theta, x_{d}, x_{s}\right)}{\partial \theta}}{r+\lambda F\left(x_{d}\right)-(r+\lambda) \frac{\partial g\left(\theta, x_{d}, x_{s}\right)}{\partial x_{d}}} \text { with } \\
g\left(\theta, x_{d}, x_{s}\right) & \equiv w\left(\theta, x_{d}, x_{s}\right)+\tau\left(\theta, x_{d}, x_{s}\right)=B\left[\frac{1}{u\left(\theta, x_{d}, x_{s}\right)\left[1-u\left(\theta, x_{d}, x_{s}\right)\right]}\right]+z-\tau_{s} \lambda F\left(x_{d}\right)
\end{aligned}
$$

It is straightforward to show that $\frac{d g(.)}{d u}<0$ if $u<0.5$, which is supposed to be satisfied. One knows from equation (22) that $u$ decreases with $\theta$ and increases with $x_{d}$. Accordingly, $g($.$) is an increasing$ function of $\theta$ and a decreasing function of $x_{d}$. Thus (JDF) has a positive slope in the $\left(\theta, x_{d}\right)$ plane as drawn in Figure 3.

Moreover, knowing that $m^{\prime}(\theta)<0, \frac{\partial g\left(\theta, x_{d}, x_{s}\right)}{\partial \theta}>0, \frac{\partial g\left(\theta, x_{d}, x_{s}\right)}{\partial x_{d}}<0$ and $\frac{\partial g\left(\theta, x_{d}, x_{s}\right)}{\partial x_{s}}>0$, differentiating equations (JDF), (JCF) and (JTF) gives:

$$
\begin{aligned}
& \frac{d x_{d}}{d \tau_{s}}=\frac{(r+\lambda)\left\{-h m^{\prime}(\theta) r+\frac{\partial g\left(\theta, x_{d}, x_{s}\right)}{\partial \theta}\left[1-F\left(x_{d}\right)\right][m(\theta)]^{2}\right\}}{h m^{\prime}(\theta)\left[r+\lambda F\left(x_{d}\right)-\frac{\partial g\left(\theta, x_{d}, x_{s}\right)}{\partial x_{d}}\right]-\frac{\partial g\left(\theta, x_{d}, x_{s}\right)}{\partial \theta}\left[1-F\left(x_{d}\right)\right][m(\theta)]^{2}}<0 \\
& \frac{d \theta}{d \tau_{s}}=\frac{[m(\theta)]^{2}\left[1-F\left(x_{d}\right)\right]\left[\frac{\partial g\left(\theta, x_{d}, x_{s}\right)}{\partial x_{d}}-\lambda F\left(x_{d}\right)\right]}{-h m^{\prime}(\theta)\left[r+\lambda F\left(x_{d}\right)-\frac{\partial g\left(\theta, x_{d}, x_{s}\right)}{\partial x_{d}}\right]+\frac{\partial g\left(\theta, x_{d}, x_{s}\right)}{\partial \theta}\left[1-F\left(x_{d}\right)\right][m(\theta)]^{2}}<0 \\
& \frac{d x_{s}}{d \tau_{s}}=\lambda F\left(x_{d}\right)+(r+\lambda)\left\{\frac{\frac{\partial g\left(\theta, x_{d}, x_{s}\right)}{\partial x_{s}}}{\left[r+\lambda F\left(x_{d}\right)-\frac{\partial g\left(\theta, x_{d}, x_{s}\right)}{\partial x_{d}}\right]}-\frac{\partial g\left(\theta, x_{d}, x_{s}\right)}{\partial x_{d}}\right\}>0
\end{aligned}
$$


Let us now turn to the welfare analysis in the flexible economy. We can show that every worker can benefit from strictly positive unemployment benefits. Given that employers set the wage unilaterally, every individual gets the same instantaneous utility level: $U(b+z)=U\left[\left(\frac{B}{u^{*}}\right)+z\right]$, where $z$ stands for the exogenous non market income, $b$ for the unemployment benefits and $u^{*}$ for the equilibrium value of the unemployment rate in the flexible economy. One assumes that the parameter values are such that $u^{*}>>0$ for $B=0$. Then, it can be shown that the instantaneous income $\left(B / u^{*}\right)$ increases with $B$ for arbitrary small values of $B$. One gets:

$$
\frac{d\left(B / u^{*}\right)}{d B}=\frac{1}{u^{*}}\left[1-\left(\frac{d u^{*}}{d B}\right)\left(\frac{B}{u^{*}}\right)\right]
$$

Since equations $(22)$ to (JCF) imply that $0<d u^{*} / d B<+\infty$, one gets $\operatorname{Lim}_{B \rightarrow \mathbf{0}}\left(d u^{*} / d B\right)\left(B / u^{*}\right)=0$ and, therefore, $\operatorname{Lim}_{B \rightarrow \mathbf{0}} d\left(B / u^{*}\right) / d B=1 / u^{*}>0$. Accordingly, the welfare of workers is improved by the introduction of unemployment benefits.

\subsubsection{Case 3: Rigid model with a minimum wage}

The definition of the equilibrium with a rigid wage is quite similar to the one depicted above. The only noticeable change is that the wage is now an exogenous variable so that $w$ is no longer a function of $\left(\theta, x_{d}, x_{n}, x_{s}\right)$. As before the equilibrium values of $\theta, x_{d}, x_{n}$, and $x_{s}$ can be defined by a system of four equations which remain identical to the ones derived above but allowing for an exogenous wage. Equations $(11),(12),(13),(15)$ and the unemployment benefits can be read as functions of $\left(\theta, x_{d}, x_{n}, x_{s}\right)$. Together with the definition of the expected value of the different types of jobs and with the job creation condition (7) and job destruction conditions (8), (9), (10), one can define the equilibrium values of $\left(\theta, x_{d}, x_{n}, x_{s}\right)$. For the sake of simplicity and since the method remains essentially the same, we implicitly boil down to the calculus developed in the previous subsection. The system is straightforward and the equilibrium values solve the four equations below. The reservation productivity $x_{d}$ satisfies:

$$
x_{d}=w+\tau\left(\theta, x_{d}, x_{n}, x_{s}\right)-r\left(f_{s}+\tau_{s}\right)-\frac{\lambda}{\lambda+r} \int_{x_{d}}^{x_{u}}\left(x-x_{d}\right) d F(x),
$$

where (JDSR) stands for the Job Destruction equation for Stable jobs in a Rigid economy.

The reservation productivity for new jobs reads as:

$$
\begin{aligned}
x_{n} & =w+\tau\left(\theta, x_{d}, x_{n}, x_{s}\right)-\left(r+\lambda\left[1-F\left(x_{s}\right)\right]\right)\left(f_{n}+\tau_{n}\right) \\
& -\frac{\lambda}{r+\alpha+\lambda} \int_{x_{n}}^{x_{s}}\left(x-x_{n}\right) d F(x)-\frac{\lambda}{r+\lambda} \int_{x_{s}}^{x_{u}}\left(x-x_{u}\right) d F(x)-\lambda\left[1-F\left(x_{s}\right)\right] \Pi_{n h}\left(x_{u}\right),
\end{aligned}
$$

where (JDNR) refer to the Job Destruction equation for New jobs in a Rigid economy.

The job creation equation is given by:

$$
\begin{aligned}
\frac{h}{m(\theta)} & =\frac{1}{r+\lambda+\alpha} \int_{x_{n}}^{x_{s}}\left(x-x_{n}\right) d F(x)+\frac{1}{r+\lambda} \int_{x_{s}}^{x_{u}}\left(x-x_{u}\right) d F(x) \\
& -F\left(x_{s}\right)\left[f_{n}+\tau_{n}\right]+\left[1-F\left(x_{s}\right)\right] \Pi_{n h}\left(x_{u}\right)
\end{aligned}
$$


where (JCR) is the Job Creation equation in a Rigid economy.

And finally the Job Transformation equation in a Rigid economy (JTR) is given by:

$$
x_{s}=x_{d}+(r+\lambda)\left(\tau_{s}+f_{s}-\tau_{n}-f_{n}\right)
$$

where $\Pi_{n h}\left(x_{u}\right)$ is worth:

$$
\begin{aligned}
\left(r+\lambda F\left(x_{s}\right)+\alpha\right) \Pi_{n h}\left(x_{u}\right) & =x_{u}-w-\tau\left(\theta, x_{d}, x_{n}, x_{s}\right) \\
& +\frac{\lambda}{r+\lambda+\alpha} \int_{x_{n}}^{x_{s}}\left(x-x_{n}\right) d F(x)+\frac{\lambda}{r+\lambda} \int_{x_{s}}^{x_{u}}\left(x-x_{u}\right) d F(x) \\
& -\lambda F\left(x_{s}\right)\left(f_{n}+\tau_{n}\right)+\frac{\alpha}{r+\lambda}\left(x_{u}-x_{d}\right)-\alpha\left(f_{s}+\tau_{s}\right) .
\end{aligned}
$$

Equations (JDNR), (JDSR), (JTR) and (JCR) (together with (26)) are the fundamental equations allowing to solve the model for $\theta, x_{d}, x_{n}$, and $x_{s}$.

\section{Appendix B: Expected utilities}

The expected present utility, $V_{s}$, of the stream of income of a worker employed on a stable job is given by:

$$
r V_{s}=U(w)+\lambda F\left(x_{d}\right)\left[V_{u}-V_{s}\right] .
$$

where $V_{u}$ denotes the expected present value of the stream of income of an unemployed worker.

The expected value of a worker on a new job with low productivity $\left(x\right.$ such that $x_{n}<x<x_{s}$ ), denoted by $V_{n l}$, changes to $V_{u}$ with probability $\alpha+\lambda F\left(x_{n}\right)$. This job with low productivity can become a job with high productivity $\left(x\right.$ such that $\left.x_{s}<x\right)$, which expected value is denoted by $V_{n h}$, with probability $\lambda\left[1-F\left(x_{s}\right)\right]$. Thus, the expected present value, $V_{n l}$, of the stream of income of worker in a new position with a low idiosyncratic productivity component solves:

$$
r V_{n l}=U(w)+\lambda\left[1-F\left(x_{s}\right)\right]\left(V_{n h}-V_{n l}\right)+\left[\alpha+\lambda F\left(x_{n}\right)\right]\left(V_{u}-V_{n l}\right) .
$$

The expected value of a worker on a new job with high productivity changes to $V_{u}$ with probability $\lambda F\left(x_{n}\right)$, to $V_{n l}$ with probability $\lambda\left[F\left(x_{s}\right)-F\left(x_{n}\right)\right]$ and to $V_{s}$ with probability $\alpha$. Thus, the expected present value, $V_{n h}$, of the stream of income of a worker in a new position with a high idiosyncratic component satisfies:

$$
r V_{n h}=U(w)+\lambda\left\{F\left(x_{n}\right)\left(V_{u}-V_{n h}\right)+\left[F\left(x_{s}\right)-F\left(x_{n}\right)\right]\left(V_{n l}-V_{n h}\right)\right\}+\alpha\left(V_{s}-V_{n h}\right)
$$

An unemployed worker gets an instantaneous income $z+b$, where $z$ and $b$ represent the exogenous income of the unemployed workers and the unemployment benefits respectively. An unemployed worker expects to move back to employment with probability $\theta m(\theta)\left[1-F\left(x_{n}\right)\right]$. If employed on a new job, the

Accordingly, the expected present value, $V_{u}$, of the stream of income of an unemployed satisfies:

$$
r V_{u}=U(z+b)+\theta m(\theta)\left\{\left[1-F\left(x_{s}\right)\right]\left(V_{n h}-V_{u}\right)+\left[F\left(x_{s}\right)-F\left(x_{n}\right)\right]\left(V_{n l}-V_{u}\right)\right\}
$$

